\title{
RESUMO
}

\section{Imunologia e as perspectivas de interesse e aprendizado por estudantes dos cursos de Medicina e Odontologia}

Os estudantes relatam dificuldades na compreensão dos conceitos fundamentais de imunologia, entre os principais fatores relacionados com estas dificuldades podemos citar: os conceitos complexos inerentes à disciplina. Objetivo: Analisar o conhecimento específico em Imunologia dos alunos do $1^{\circ}$ ano do ensino superior do curso de Odontologia e Medicina e estabelecer uma relação entre a qualidade recebida anteriormente sobre esse assunto e a adquirida após as aulas da disciplina de Imunologia. Metodologia: Na primeira avaliação, os alunos responderam a um questionário que foi aplicado a um total de 81 estudantes vinculados aos cursos de Medicina (36 alunos) e Odontologia (45 alunos) da Faculdade de Odontologia de Bauru, Universidade de São Paulo (FOB/USP). Na segunda avaliação, para o estabelecimento da mudança conceitual dos estudantes, aplicou-se o mesmo questionário do levantamento de concepções da primeira etapa do trabalho. Resultados: Verificamos para o curso de Odontologia durante a $1^{\text {a }}$ avaliação que mais de $50 \%$ de acertos estavam relacionados com questões fáceis, $45 \%$ questões intermediárias e apenas $15 \%$ das questões difíceis. Na segunda avaliação, os resultados evidenciaram uma melhora significativa na porcentagem de acertos, uma vez que, das oito questões propostas, todas tiveram um predomínio acima de $80 \%$ de acertos. Em relação aos resultados para o curso de Medicina, na $1^{\text {a }}$ avaliação, os resultados evidenciaram que mais de $50 \%$ de acertos estavam relacionados com questões fáceis, $35 \%$ questões intermediárias e $25 \%$ das questões difíceis. $\mathrm{Na}$ segunda avaliação verificamos uma melhora nos acertos das questões mais fáceis e intermediárias e para as questões mais complexas, houve melhora, mas não muito significativa de $25 \%$ para $29 \%$. Conclusão: Após a análise, podemos verificar a presença de concepções prévias pelos alunos de conceitos básicos de imunologia.

Palavras-chave: Ensino-aprendizagem. Concepções prévias. Sistema imunológico. 